\section{CONVERGENCE DEFICIENCY}

\section{THE CONDITION, ITS OCCURRENCE IN PRIVATE PRACTICE, AND THE RESULTS OF TREATMENT*}

\author{
BY
}

IDA MANN, D.Sc., F.R.C.S.

Surgeon, Royal London Ophthalmic Hospital; Ophthalmic Surgeon, Royal Free Hospital

I propose to deal briefly with certain practical clinical aspects of convergence deficiency, with special reference to a group of cases characterized by the fact that they show a divergence of 6 degrees or more (exophoria) on the Maddox wing test and failure of voluntary convergence. Such cases may with the Maddox rod show orthophoria, exophoria, or esophoria. They may be of any age from 6 to 70 years and may or may not complain of symptoms. The condition has been investigated by other observers, notably Berens, Hardy, and Stark, who, in 1929 summarized the literature and analysed over 11,000 of their own private case sheets. They came to the conclusion that " a review of the literature concerning the condition ... revealed a wide variance of opinion regarding almost all the factors connected with it." From their own practices they arrived at the following figures:

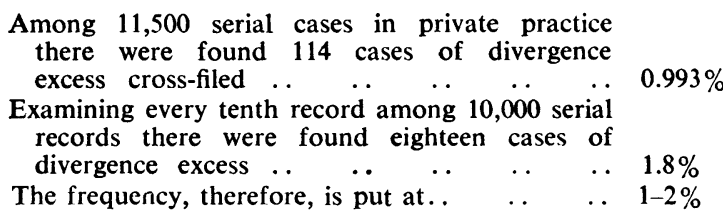

In my series I found a percentage of between 2 and 3 . The exact figure cannot be worked out more accurately, as a number of cases were border-line with a deviation of 6 degrees and few or no symptoms. Undoubted cases formed 2.6 per cent. (167 out of 6,400 ), which is slightly higher than Berens's figure, but it is obvious that individual surgeons will vary slightly in what they include. I was myself always hunting for cases, and so have probably included more border-line ones than other observers. Of the 167 cases not all were treated and not all carried out the treatment. The following conclusions are therefore drawn from the eighty-two cases from among them which I have more thoroughly investigated.

We are all acquainted with the type of patient who complains of suffering constantly from "eye-strain," of being unable to engage in any close work for long at a time, and of gaining little or no help from glasses. Such patients often arrive with a sheaf of prescriptions and a handbag full of spectacles, and our hearts sink when they are produced. The majority of them show a very lowgrade hypermetropic astigmatism and nothing else, other than deviation outwards on the Maddox rod and failure to perform convergence as a voluntary action. In my series there was no possible correlation with age, sex, or refraction, cases being distributed evenly over all the age periods of ten years, from 6 onwards, and the types and numbers of refractive error being those in the general population.

Seventy-one of the eighty-two cases analysed in my series were treated by orthoptic exercises, and the results were as follows:

* Abstract of a paper read to the Section of Ophthalmology at the Annual Meeting of the British Medical Association, Aberdeen, 1939.

\begin{tabular}{|c|c|c|c|c|c|}
\hline & & Treated & Cured & Improved & No Change \\
\hline Symptomatic & $\left\{\begin{array}{l}\text { Hypermetropes } \\
\text { Myopes } \\
\text { Anisometropes }\end{array}\right.$ & $\begin{array}{r}52 \\
14 \\
5\end{array}$ & $\begin{array}{r}37 \\
8 \\
3\end{array}$ & $\begin{array}{r}14 \\
5 \\
2\end{array}$ & $\begin{array}{l}1 \\
1 \\
-\end{array}$ \\
\hline Objective & $\left\{\begin{array}{l}\text { Hypermetropes } \\
\text { Myopes } \quad . . \\
\text { Anisometropes }\end{array}\right.$ & $\begin{array}{r}52 \\
14 \\
5\end{array}$ & $\begin{array}{r}31 \\
6 \\
3\end{array}$ & $\begin{array}{r}18 \\
7 \\
2\end{array}$ & $\begin{array}{r}3 \\
1 \\
-\end{array}$ \\
\hline Totals & $\left\{\begin{array}{l}\text { Symptomatic } . . \\
\text { Objective }\end{array}\right.$ & $\begin{array}{l}71 \\
71\end{array}$ & $\begin{array}{l}48 \\
40\end{array}$ & $\begin{array}{l}21 \\
27\end{array}$ & $\begin{array}{l}2 \\
4\end{array}$ \\
\hline
\end{tabular}

These figures agree with those of Berens, Hardy, and Stark in that they show a high percentage of cures and improvements following treatment and also in the illuminating fact that it is possible to produce apparent alleviation of all the symptoms without providing any objective cure. This is only one more argument in favour of the already recognized fact that neurasthenia and other psychological factors account for many of the symptoms, and it brings us to the statement of the main clinical problem which I have tried to elucidate. This is, stated simply, the relation of the subjective symptoms ("eye-strain," inability to read with comfort, headache, and sometimes photophobia) to the objective signs (exophoria of more than 6 degrees on the Maddox wing and failure to perform binocular convergence as a voluntary action). That this is a definite problem is seen from the undoubted facts (1) that the objective signs can exist for years without any symptoms at all ; (2) that cure of the signs does not necessarily produce disappearance of the symptoms; (3) that the symptoms may disappear entirely while the signs remain unaltered; (4) that relapse and recurrence of the symptoms may occur without reappearance of the objective signs; and, finally, (5) that cases exist with all the classical symptoms and no objectively demonstrable signs at all. Cases can be cited exemplifying these various points.

The treatment of the symptoms of eye-strain is therefore not so simple as one might imagine. It would be possible to argue from actual cases that there is no proof whatever of connexion between the signs and symptoms, and that we are dealing with entirely separate conditions that happened to coexist. However, I think we are justified in admitting some connexion in view of the high percentage of cases in the table in which alleviation of the symptoms was associated with disappearance of the signs.

\section{Aetiological Theories}

It is well known that from an evolutionary point of view increasing binocular overlap of the fields of vision appears to be correlated with increasing neopallial development in the central nervous system. This has been pointed out again and again by anatomists such as Brouwer and Elliot Smith. That the correlate of binocular overlap is neopallial increase and not increase in complexity of the eye is shown by the condition in the primitive reptile Sphenodon, which has a good macula but a primitive brain and no binocular overlap. Now, the overlap increases until stereoscopic vision becomes possible with superposition of the central areas of both fields. The final and highest form of binocular vision can therefore be considered to arise when by voluntary muscular action the animal can increase the overlap of the fields so as to obtain stereoscopic vision at the near point. This occurs so late in evolution that it is probable that only man shows it and certain that not all individuals attain it. It is also well known that some movements which are primarily largely reflex and involuntary can by practice be brought under voluntary control. Elliot Smith, Wood Jones, and other anatomists have shown that such volun- 
tary control is dependent on the existence of cerebral connexions whereby the lower centres are linked with the cortical areas controlling such movements. In most people such connexions exist, though in many they are not consciously used but can be made use of by practice.

The exact cerebral localization of function such as was envisaged by Sherrington, Horsley and Beevor, and Campbell is probably not capable of complete proof, while the work of Poljak seems to show that there is in the production of even the simplest efferent impulse a generalized activity of the whole cortex. In Gordon Holmes's valuable paper "The Cerebral Integration of the Ocular Movements" we have a most lucid account of the present state of our knowledge of the anatomical pathways involved. Beevor and Horsley's centre for eye movements in monkeys lies in the frontal lobe, separated by unexcitable cortex from the precentral gyrus. This appears to be also the case in man, though destruction, if unilateral, does not produce palsy. In addition to this centre there is another in the occipital lobe, close to but within the area striata. Fibres from here pass to the anterior corpora quadrigemina in the neighbourhood of the oculomotor nuclei. They descend medial to the optic radiations and pass through the pulvinar and anterior brachium to the tectum of the midbrain. Thus there are two cortical areas (frontal and occipital) involved in eye movements. The frontal area appears to govern voluntary movements, and if it is destroyed the patient cannot look in a certain direction to command, though he can follow a moving object, since his fixation reflex is mediated by the intact occipital centre. If the occipital centre is destroyed the fixation reflex is lost, though the patient can perform voluntary movements of the eyes. Fixation is largely reflex, but requires the intervention of consciousness. All authors from Ferrier onward have stressed the necessity for active "attention" in the acts associated with vision. Gordon Holmes says: "It is only the object which occupies attention that excites the fixation reflex." The movements of convergence are of the same nature, both conscious and reflex, and for the attainment of binocular stereoscopic vision of a near object both centres come into play. Gordon Holmes says of the frontal centre: "Through it we can by an effort of will look or turn our eyes in any direction and converge them on a near object. By it, too, we can keep our eyes directed on any object that interests us, though this is largely a function of the occipital cortex." In the cases under consideration it is likely that what we are doing or trying to do is to increase the permeability of the frontal path by "facilitation," using conscious attention as the stimulus and the fixation reflex as the source of the impulse. This is of course much older and very much more firmly established phylogenetically, than the frontal side of the complete reflex.

The contraction of both internal recti together may therefore never be under voluntary control, or it may be under partial voluntary control in that it occurs in association with accommodation when called forth by the fixation reflex when the child wishes to look at a near object, or it may from a quite early age be both reflex (when looking at a near object) and purely voluntary when it is done as a trick from the frontal centre alone. This, the power of using convergence either as part of the reflex of complicated co-ordinated movements required in reading or as a purely voluntary single movement, constitutes the highest possible development of the area of cortical re-representation of the eye movements in man. A study of a series of children has seemed to show that it is normally acquired at about the age of 6 and that symptoms may be developed if it is delayed. These cases give excellent results with orthoptic treatment, and up to the age of 24 all patients in the series obtained normal voluntary and involuntary convergence. Above this age one found an increasing number of patients showing mental instability, and it is uncertain whether they are examples of delayed development also or whether they were originally orthophoric and have broken down.

Many of the psychopaths refused treatment or did not carry it out, but, apart from these, there were a large number of adults who conscientiously did the exercises and were cured both objectively and symptomatically.

\section{Length and Nature of Treatment}

The length of time needed to get the maximum result is least in the intelligent children and the young adults. In older adults, as one would expect, it is longer. The maximum time taken to produce an amplitude of fusion of 60 degrees on the synoptophore and a Maddox wing deviation of less than 6 was a year in an adult of 63 , while the shortest time was twelve days in a young man very anxious to get into the Air Force. Most cases took just over a month. This does not mean many visits if the patient will work at home. About four visits are usually necessary. Practically all the cases I treated myself, as those few which I sent to orthoptic trainers took, on the average, many more visits.

The treatment employed was based on the belief that as we are trying to establish a movement which is normally dual in nature, being both part of an unconscious reflex and also capable of being performed voluntarily, two methods of approach are possible. We can increase the power and amplitude of the reflex until it becomes conscious, or we can endeavour to show the patient how to perform the voluntary action first and to relegate it to the level of a reflex again later when it has been mastered. Both methods appear to give identical results, and one may be better than the other in certain cases. The first is applicable to children and to adults without much insight. The second, to my mind, is preferable, as it is in my experience invariably shorter and more satisfying to the patient. Actually I always use a combination of the two in varying proportions. The first method includes graduated exercises in fusion on the synoptophore (Maddox and othęrs), exercises with prisms to produce convergence for distance (kinetic treatment of Stutterheim), and exercises with a stereoscope and figures of graduated spacing and difficulty (as in the Hamblin and Wells series). All these methods increase the involuntary range of convergence.

The second method aims at stimulating the patient's appreciation of the proprioceptive impulses from the eye muscles so that he learns first to recognize the position of his eyes and thus quite soon to be able to control this. The principal procedures are the education of the patient in the appreciation of physiological diplopia and the control of this, exercises with the small diploscope, and exercises in the fusion of stereoscopic cards without a stereoscope. If retinal neglect is present the Wells $G$ series of cards in a stereoscope is used until it disappears. The advantage in beginning with the second method is the amount of time saved. I first became interested in the whole problem as the result of some correspondence with Dr. Stutterheim of Johannesburg, the author of Eye Strain and Convergence. I then used his method of fusion of a distant object against prisms, base out, and also an arrangement of rotating prisms in a trial frame 
which produced a somewhat similar result. The treatment sometimes took a few months; Stutterheim himself states that twenty-four visits are usually necessary, but as many as ninety may be required, though I never actually saw a patient more than fourteen times. Even this I considered far too high, and therefore attempted by education of the proprioceptive sense to shorten the treatment and to give the patient more to work on at home. I then found that if one began this way round the average number of visits was four and the time one to two months or less.

In conclusion I wish to emphasize the clinical importance of absence or weakness of voluntary convergence and to point out the fact that it is among the most easily treated of the heterophorias.

\section{Summary}

This paper is an analysis of 6,400 case sheets of private patients with reference to the frequency of the type of patient presenting exophoria at reading distance on the Maddox wing test and absence of the power of voluntary convergence. There were 2.6 per cent. of cases, and these are analysed into groups according to age, to refraction, and to type of patient.

The cerebral localization of the centres concerned in convergence is considered and the evolutionary value and meaning of the movement. Treatment and its results are dealt with. The conclusions agree in the main with those of other observers in that it can be shown that the condition is due to a developmental lag (functional, not anatomical), and that neither age nor accompanying error of refraction has any influence on its occurrence. In most individuals educative treatment of the cerebral centres and facilitation of the reflex by exercises have a marked beneficial effect.

\section{RESULTS OF AMBULANT TREATMENT OF PEPTIC ULCERS}

\author{
BY
}

\section{DAVID FERRIMAN, D.M., M.R.C.P.}

Late Medical Registrar, Westminster Hospital

Lack of beds has been a great handicap in the work of voluntary hospitals, yet it has led to one considerable advance in medical treatment. Davies (1936) was obliged to treat sufferers from peptic ulcer as out-patients, and he found that healing was obtained in the great majority. The economic saving to such patients was considerable: the usual previous in-patient treatment, though probably effective in a higher proportion of cases, necessitated a long rest in bed and was a severe financial strain on many patients.

Davies was concerned primarily with the part played by nervous disturbances in the production of peptic ulcer. The hypothesis is an ancient one. Fresh supporting evidence has been supplied in the last few years. Two clinical papers by Davies and Macbeth-Wilson (1937, 1939) attempt to establish the connexion. Recent animal experiments indicate the physical channels through which the mind may affect the stomach. Hoff and Sheehan (1935) found haemorrhagic erosions and gastric ulcers following stimulation of the hypothalamus. Mettler and his coworkers (1936), after ablation of part of the cortex anterior to the pyramidal region, found petechial haemorrhages and later gastric ulcers.

It is possible to ascribe the healing of ulcers under various medical regimes solely to factors which, like rest, may exert their effects through the mind, and to deny the value of diet and alkalis. A series of controlled experiments on dogs suggests that this is untrue. Stalker and others (1937) showed that a milk diet-as opposed to the ordinary kennel diet-alkalis, and more particularly a combination of both, inhibited the development of ulcers after the giving of cinchophen. It would be inadvisable, therefore, to neglect such factors in the treatment of peptic ulcer.

\section{Treatment in the Present Series}

Forty-two patients with uncomplicated chronic gastric or duodenal ulcers have been treated since 1936 at Westminster Hospital along the lines advocated by Davies. The results are not as complete as could have been wished, owing to the outbreak of war ; they are, however, satisfactory and clear-cut.

The outline of treatment is as follows. The patients went to work in the ordinary way. They were forbidden red meat, all "spices" and spicy foods, and alcohol; tobacco was restricted to a maximum of ten cigarettes a day. Six meals a day were rigorously enjoined. Alkalis were only taken when the patients experienced any pain. A mixture of magnesium carbonate and bismuth oxycarbonate was usually employed, in some cases magnesium hydroxide alone. Olive oil was never prescribed. Tincture of belladonna was ordered in about half the cases. Some of the patients were put on bromide and phenobarbitone; otherwise no systematic attempt was made to deal with mental factors: with more attention to this point results might have been better. The patients reported for some time at fortnightly intervals. They were apt to misunderstand or neglect parts of the regime ; frequent consultations led to more rapid imposition of the regime and so to earlier symptomatic relief. As soon as this had been achieved they returned monthly. Radiographs were taken every three months, and strict treatment was continued for some time after the disappearance of radiological signs of an ulcer (see below): no set rule was observed in the matter. After this some relaxation was permitted. Veal, lamb, and mutton were readmitted to the diet. Alcohol was allowed in moderation and tobacco up to twenty cigarettes a day. The patients reported at three-monthly intervals. Those cases in which little or no healing was visible at the end of a year were considered failures on this line of treatment.

The original clinical diagnosis was confirmed in all cases by radiographs. "Radiological cure" was considered to have taken place when the crater and all signs of localized tenderness and spasm had completely disappeared.

\section{Results}

Of the forty-two patients two abandoned treatment and one had a perforation, for which an operation was performed successfully: no other perforation or haemorrhage occurred in the series. Of the remaining thirty-nine cases twenty-three progressed to " radiological cure," seven were failures, and in nine the data are incomplete (Table I). The ratio of cures to failures is high. Nearly all cases, whether ultimate successes or failures, lost their pain as soon as the full regime had been established.

TABle I.-Outline of Results

\begin{tabular}{c|c|c|c}
\hline Successes & Failures & Data Incomplete & Total \\
\hline 23 & 7 & 9 & 39 \\
\hline
\end{tabular}

Of the nine in whom the data are incomplete six showed definite radiological improvement. In several of the 